\title{
Sensorial character of beer dry hopped with new Czech genotypes of hops with a specific flavor
}

\author{
Lenka Straková1 ${ }^{1}$ Vladimír Nesvadba ${ }^{3}$, Jindřich Křivánek ${ }^{4}$, Martin Slabý², Tomáš Vrzal², Jitka Charvátová3, \\ Radim Cerkal ${ }^{1}$, Jana Olšovská2* \\ Mendel University in Brno, Faculty of AgriSciences, Zemědělská 1 , \\ CZ - 61300 Brno, Czech Republic \\ 4 HOP PRODUCTS, Ltd., Josefa Ressla 1469/2, \\ Research Institute of Brewing and Malting, Plc., \\ Lípová 15, CZ - 12044 Prague 2, Czech Republic \\ 3 Hop Research Institute Co., Ltd., Saaz, Kadaňská 2525, \\ CZ - 43801 Žatec, Czech Republic \\ CZ - 43401 Most, Czech Republic \\ *Corresponding author: olsovska@beerresearch.cz
}

\begin{abstract}
In the Czech Republic breeding of new hop varieties is traditionally performed. Its properties correspond with the requirements and interests of end users, in particular hop growers, brewers and especially beer consumers, who with an increasing favor taste new types of beer. The study presents 8 new promising aromatic genotypes, whose major part (Uran, Juno, Ceres, Jupiter, Eris and Most) is already in the registration process of ÚKZÚZ of the Czech Republic (Central Institute for Supervising and Testing in Agriculture CISTA). The tested genotypes were described using brewing tests. Regarding the character of the tested hop varieties, there was chosen a uniform and simple infusion recipe with a top fermentation and dry hopping. The final beer samples were evaluated using chemical and sensorial analyses focusing on a hop aroma. All beer samples were rated as very good, the overall impression of the samples on the scale of 1 to 9 ranged from 2.9 to 3.1. The hop aroma and also bitterness character of the final beer samples were evaluated of high quality. Depending on the hop profile of the beer samples, there were suggested beer styles where the given varieties can be successfully used. These results indicate a high potential of these varieties for the use in brewing practice. Finally, the probability of perceiving a particular hop aroma in beer given by perceiving the aroma in hops was determined by Bayes' theorem. It was found that probability particularly for spicy, resinous, herbal, citrusy, floral, fruity and grassy aroma was $100,100,100,40,38,43$, and $100 \%$, respectively.
\end{abstract}

Key words: hop, breeding, aroma, new hop genotypes, brewing test, Bayes' theorem

\section{Introduction}

Hop breeding must reflect the requirements of especially its target users, namely hop growers, brewing technologists and beer consumers. Therefore, the goal of breeding of new varieties was and still is a variety with good resistance to diseases and pests, high crop yield and stability of quantitative and qualitative parameters, such as signs of growth that ensure good productivity of cultivation and especially good sales.

Czech hop growing is historically associated with the cultivation of aromatic hop varieties. Saaz (Semi-early red bine hop) has been considered for centuries as aromatic hops with the best quality in the world. Therefore, for several decades hop breeding was focused on the Saaz hops, and in time there were registered its new successful clones (Fric, 1992). For its unmistakable aroma this hop variety is used worldwide in production of lager-style beer. It is often referred to as the standard of quality of the real, gentle hop aroma with a predominantly spicy and lemon character.

The second phase in hop breeding was the introduction of the crossing method in the 1950s (deliberate crossing of male and female plants in order to obtain an offspring with higher productivity, resistance, stability, etc.). In this way 
there was bred and registered a number of aromatic (Brewer, Premiant, Harmonie, Saaz Late, Country, Blues, Saaz Comfort, etc.) and bitter hop varieties with a higher content of alpha acids (Agnus, Vital, Rubin, Boomerang, Gaia). The hop crossing method is still used for breeding of new hop varieties in the Czech Republic (Nesvadba et al., 2017).

In recent years, there has been a great interest in hops with a specific aroma (flavor hops), i.e. not typical hop aroma (citrusy, fruity, woody, herbal, floral, etc.). This group includes the varieties with a good application especially in production of modern types of beer, such as Kazbek and Mimosa.

Since 2012, a number of hop crossings have been conducted for breeding of new hop genotypes with a high intensity of a specific flavor (Nesvadba, 2018). The basis of breeding is a collection of genetic resources of hops which is a part of the National Program for the Conservation and Utilization of Plant Genetic Resources and Agrobiodiversity (Charvátová et al., 2017). The collection includes all the world varieties of hops as well as wild hops, which began to be used in breeding due to their specific aroma. The most commonly used varieties are Kazbek, Columbus, Cascade and wild hops from North America.

Few promising new genotypes of hops tested from the growing and brewing point of view was obtained. The best genotypes are already being tested in field conditions and also in large and small breweries, where some successful recipes have already been developed. Many of them regularly appear not only in the offer of some pivots and tasting pubs but also in the program of "The brewer's choice" (Volba sládků in Czech) of Plzeňský Prazdroj, Czech Republic.

The aim of this study was to describe the qualitative parameters of the selected hop genotypes in beer using brewing tests. Due to the nature of the tested hop varieties, a simple infusion recipe with top fermentation and dry hopping was chosen for the study. The final beer samples were analyzed by chemical and sensory analyses.

The following genotypes were chosen for the study:

HP 111 (Most) A selection of this variety was carried out in 2010. It originates from the mass selection of Cascade and developed breeding material. Hop plants are of the medium habitus with medium long lateral of the cylindrical shape. Elongated cones are of the medium size. Their density is scarce to medium. It is a semi-late variety.

The aroma of hop cones is medium intense to intense, slightly fruity (grapefruit, tropical fruit, mango, peach, black currant, slightly citrus), spicy and hoppy. The content of alpha acids, beta acids, cohumulone and essential oil is ranging from 7 to $10 \% \mathrm{w} / \mathrm{w}, 3$ to $4 \% \mathrm{w} / \mathrm{w}, 27$ to $31 \%$ rel. and 1.0 to $1.6 \% \mathrm{w} / \mathrm{w}$, respectively.
5164 (Uran) was crossed in 2006 after Columbus and developed breeding material. Hop plants are vigorous with long laterals of the club shape. Cones of the elongated shape are large, firm, and very heavy. The density of cones is medium. It is a late variety.

The aroma of hop cones is very intensive, sharply hoppy, spicy (black pepper, curry, star anise), vegetably (garlic, onion, olive), herbal, resinous (needles). The content of alpha acids, beta acids, cohumulone and essential oil is ranging from 10 to $14 \% \mathrm{w} / \mathrm{w}, 5$ to $7 \% \mathrm{w} / \mathrm{w}, 24$ to $30 \%$ rel. and 1.3 to $2.0 \% \mathrm{w} / \mathrm{w}$, respectively.

5495 (Juno) was bred in 2012 from Kazbek and wild hops from Canada. Hop plants are of the medium habitus, cylindrical shape and medium long laterals. Cones of the egg shape are the medium size and closed. The density of cones is medium. It is a semi-late variety.

The aroma intensity of hop cones is medium, fruity sweet (mango, banana, watermelon), with a flavor of apple, orange, citrus fruits, herbal. The content of alpha acids, beta acids, cohumulone and essential oil is ranging from 4 to $6 \% \mathrm{w} / \mathrm{w}, 3$ to $5 \% \mathrm{w} / \mathrm{w}, 35$ to $45 \%$ rel. and 0.6 and $1.2 \% \mathrm{w} / \mathrm{w}$, respectively.

5512 (Ceres) was released in 2012. It originates from Kazbek and breeding material of a European origin. Hop plants are of the medium spindle-cylindrical-shaped habitus with medium long laterals. Cones of the medium size are closed and oblong. Their density is medium. It is a semi-late variety.

The hop aroma intensity of cones is medium, mixture of fruity (apple, pear, orange, grapefruit, lime), woody (bark, tobacco), and grassy (tomato leaves, grass, nettle and herbs). The content of alpha acids, beta acids, cohumulone and essential oil is ranging from 4 to $7 \% \mathrm{w} / \mathrm{w}, 3$ to $5 \% \mathrm{w} / \mathrm{w}, 32$ to $42 \%$ rel. and 0.7 to $1.3 \% \mathrm{w} / \mathrm{w}$, respectively.

5540 (Jupiter) was released in 2013. It is the result of a crossing between Kazbek and breeding material of a world origin. Hop plants are medium to vigorous of the cylindrical to club shape with long laterals. Cones are medium large to large, closed and have the oblong shape. The density is high.

The aroma intensity of hop cones is medium, mixture of floral (jasmine, rose), herbal (mint, lemon peel), spicy, fruity (apple, peach). The content of alpha acids, beta acids, cohumulone and essential oil is ranging from 3 to $7 \% \mathrm{w} / \mathrm{w}, 2$ to $4 \% \mathrm{w} / \mathrm{w}, 27$ to $34 \%$ rel. and 0.4 to $0.9 \% \mathrm{w} / \mathrm{w}$, respectively.

5571 (Eris) was bred in 2013 from Kazbek and a mass selection of Fuggle. Plants are of the medium size, cylindrical to club shape, with long lateral. Cones are 
medium size of the egg shape, slightly closed and elongate. The density of cones is scarce to medium. It is a late variety.

The intensity of aroma of hop cones is very intensive, citrusy (lime, grapefruit, tangerine, orange, peel of citrus), floral, herbal and black currant. The content of alpha acids, beta acids, cohumulone and essential oil is ranging from 5 to $8 \% \mathrm{w} / \mathrm{w}, 4$ to $6 \% \mathrm{w} / \mathrm{w}, 30$ to $44 \%$ rel. and 0.7 to $1.3 \% \mathrm{w} / \mathrm{w}$, respectively.

Cross No. 5652 was released in 2015. It originates from Kazbek and breeding material of a European origin. Hop plants are vigorous of the club shape with long laterals. Cones of an oval shape are large, firm and heavy. The density of cones is medium. It is a semi-late variety.

The aroma intensity of hop cones is medium, gently, fruity, floral, herbal. The content of alpha acids, beta acids, cohumulone and essential oil is ranging from 5 to $8 \%$ w/w, 4 to $6 \% \mathrm{w} / \mathrm{w}, 30$ to $40 \%$ rel. and 0.8 to $1.5 \% \mathrm{w} / \mathrm{w}$, respectively.

Cross No. 5656 originates from Kazbek and breeding material of a European origin (sister of Crossing No. 5652). Hop plants are vigorous of the cylindrical shape with long laterals. Cones are of the medium size, firm, elongated and medium heavy. The density of the cones is high. It is a semi-late variety.

The aroma intensity of hop cones is strong, fruity (tropical, citrus, mango) and herbal (mint, needles). The content of alpha acids, beta acids, cohumulone and essential oil is ranging from 6 to $9 \% \mathrm{w} / \mathrm{w}, 3$ to $5 \% \mathrm{w} / \mathrm{w}, 33$ to $43 \%$ rel. and 1.3 to $2.0 \% \mathrm{w} / \mathrm{w}$, respectively.

\section{Materials and methods}

\section{Hop growing}

Hop plants were grown at a minimal number of thirty at the same locality in the spacing of $300 \times 114 \mathrm{~cm}$. Growing conditions and agro-technical operations were always the same, therefore, quantitative and qualitative features were not environmentally influenced, and so they characterize the particular variety. Each genotype was planted separately. Hop plants were harvested by a pilot picking machine "Wolf" (Anlagen-Technik, Germany). The coefficient of dry matter from raw to dry hops was 4.

Hop garden of HP 111 Most variety was located at $50^{\circ} 28^{\prime} 80.67^{\prime \prime} \mathrm{N}$ and $13^{\circ} 71^{\prime} 98.64^{\prime \prime} \mathrm{E}$, the hop gardens of the other varieties were at $\mathrm{N} 50^{\circ} 19.84582^{\prime}$ and E $13^{\circ} 35.72938^{\prime}$.

\section{Beer technology}

Three beer batches (A, B and C) were prepared in a Kaspar-Schulz (Germany) research brewhouse with a maximum capacity of $250 \mathrm{~L}$ using the same brewing recipe as described below. The grist composition for each brew was $34 \mathrm{~kg}$ of Pale Ale malt from the Germany Bestmalz malthouse (extract-dry basis $80.5 \%$, color 6 EBC). The volume of cold wort was approx. $210 \mathrm{~L}$. An infusion mashing regime was used with the mash-in temperature of $52^{\circ} \mathrm{C}$ and the rest of $5 \mathrm{~min}$, followed by heating to $68{ }^{\circ} \mathrm{C}$ with the temperature gradient of $1{ }^{\circ} \mathrm{C} / \mathrm{min}$ and the rest of $25 \mathrm{~min}$. This was followed by heating to mash-out temperature of $77^{\circ} \mathrm{C}$ with the temperature gradient of $0.7{ }^{\circ} \mathrm{C} / \mathrm{min}$. A standardized lautering process was controlled according to the clarity and pressure difference below and above the false bottom. The maximum turbidity of sweet wort was set to $20 \mathrm{EBC}$ and the last running to $50 \mathrm{EBC}$. The volume of sweet wort before boiling was $220 \mathrm{~L}$. The atmospheric wort boiling duration was $80 \mathrm{~min}$

Two beer batches (A and B) were hopped only with $\mathrm{CO}_{2}$ extract from the Hercules variety. The third beer batch (C) was hopped with T90 type pellets prepared from the Most variety. The bitterness target in the beer was $30 \mathrm{BU}$.

All three beer batches were fermented identically at $20^{\circ} \mathrm{C}$ with Lallemand's Essential series ALE yeast as these yeasts don't form large amounts of esters. Maturation took place in a lager cellar at $2{ }^{\circ} \mathrm{C} \pm 0.5{ }^{\circ} \mathrm{C}$ for 16 days.

The batches A and B were mixed together and then divided into eight equal portions and filled into Kegs where dry hopping was done by an addition of the studied genotypes with the dosing rate of $2.5 \mathrm{~g} / \mathrm{l}$ for 5 days. It was then filtered on the plate filter with S10N filter plates (Hobra Školník, Broumov) and bottled without the access of oxygen.

Since there were enough hops of the Most genotype for the study, an additional experiment was performed with the batch $\mathrm{C}$ which was dry hopped with pellets of this variety. The other steps were the same as for the batches $\mathrm{A}$ and $\mathrm{B}$. In the last step, the batch $\mathrm{C}$ was divided into 2 portions, the first portion was dry hopped with the Most variety ( $2.5 \mathrm{~g} / \mathrm{l})$ for the last 5 days, the second portion was left unchanged. Both alternatives were finally filtered on the plate filter with S10N filter plates (Hobra Školník, Broumov) and packed into bottles without the oxygen access.

For clarity, the designation of beer samples and ways of their preparation are given in Table 1. 
Table 1 List of experimental beer samples, designation (number and name of the genotype) and used hopping technology

\begin{tabular}{|c|c|c|}
\hline Beer No. & Genotype ${ }^{\text {a }}$ & Hopping technology \\
\hline 1 & HP 111 Most & dry hopping of mixed batches (A+B) \\
\hline 2 & 5164 Uran & dry hopping of mixed batches (A + B) \\
\hline 3 & 5495 Juno & dry hopping of mixed batches (A + B) \\
\hline 4 & 5512 Ceres & dry hopping of mixed batches (A+ B) \\
\hline 5 & 5540 Jupiter & dry hopping of mixed batches (A+B) \\
\hline 6 & 5571 Eris & dry hopping of mixed batches (A + B) \\
\hline 8 & 5656 & dry hopping of mixed batches (A + B) \\
\hline 9 & 5652 & dry hopping of batch C \\
\hline 10 & HP 111 Most & batch C without dry hopping \\
\hline
\end{tabular}

${ }^{a}$ used for dry hopping

\section{Chemical analysis of beer}

The determination of the original extract was performed according to the EBC 9.4 method and the determination of bitterness according to the EBC 9.8 method.

The content of alpha and beta acids in hops was analyzed using HPLC (High Performance Liquid Chromatography) according to the EBC 7.7 method.

The content of iso-alpha acids in beer was analyzed using HPLC according to the EBC 9.47 method.

The profile and concentration of particular hop oils in hops and beer were determined by GC-MS (gas chromatography with mass detection) according to a previously published method (Štěrba et al., 2015).

\section{Sensory analysis of beer}

Sensory analysis of beer was performed by the expert 12-member panel of the Research Institute of Brewing and Malting (RIBM). The panel assessors were selected and trained in compliance with ISO 8586:2015 and ISO $11132: 2012$. Sensory analysis was performed in the sensory laboratory according to the EBC 13.2 method and ISO 8589:2008 (General Guidance for the Design of Test Rooms). The samples were served in tasting glasses and tempered to $10 \pm 2{ }^{\circ} \mathrm{C}$.

Both, a basic profile and profile of hop aroma of beer were evaluated. The intensity of bitterness, bitterness culmination (after $15 \mathrm{~s}$ ), bitterness aftertaste (after $40 \mathrm{~s}$ ) and bitterness character were evaluated on the scale from 0 to 5 , where 5 is the maximum. The same scale was applied for astringency, sweetness and sourness. The overall impression of beer was rated on the scale of 1 to 9, where 1 was the best beer.

The intensity of hop aroma and intensity of particular hop flavors were evaluated on the scale from 0 to 5 (0-none, 5-maximum).
The evaluation of the assessors was processed using a method of trimmed average (minimum and maximum values were excluded). Due to a large amount of obtained data, they are not shown in detail, however, the data are discussed in the "Results and Discussion" section.

\section{Data processing}

The evaluation of a transfer of a hop aroma into beer during dry hopping was evaluated by a calculation of conditional probability that beer had a particular aroma given the fact that this aroma was perceived in hops. A verbal description of the basic classes of hop aroma (spicy, resinous, herbal, citrusy, floral, fruity and grassy) in the Table 5 was transferred to a binary numerical form. The point estimation of the probability was calculated by the Bayes' theorem (Bayes and Price, 1763) with an uninformative prior probability.

\section{Results and discussion}

\section{Chemical analysis of hops}

The content and profile of hop resins from nurseries (genotypes Uran, Juno, Ceres, Jupiter, Eris, No. 5652 and No. 5656) in 2019 and the long-term average of these compounds in the genotype Most are given in Table 2 . The highest content of alpha acids was found in the genotypes Uran $(10.26 \% \mathrm{w} / \mathrm{w})$, No. $5656(8.01 \% \mathrm{w} / \mathrm{w})$ and Most (long-term rating from 7.5 to $9.5 \% \mathrm{w} / \mathrm{w}$ ). Simultaneously, these genotypes had the ratio of alpha/beta acids higher than 2 . The genotype Jupiter had the lowest content of alpha acids (3.37\% w/w and simultaneously also the lowest alpha/beta acids ratio, namely 1.09). Only genotypes Uran a Jupiter had a percentage of cohumulone lower than $30 \%$ rel., the genotype Most ranges at this level. 
Table 2 Analysis of hop resins in tested genotypes 2019

\begin{tabular}{|c|c|c|c|c|c|}
\hline genotype & $\begin{array}{c}\text { alpha acids } \\
(\% \mathrm{w} / \mathrm{w})\end{array}$ & $\begin{array}{l}\text { beta acids } \\
(\% \mathrm{w} / \mathrm{w})\end{array}$ & $\begin{array}{l}\text { ratio } \alpha / \beta \\
(\% w / w)\end{array}$ & $\begin{array}{c}\text { cohumulone } \\
\text { (\% rel.) }\end{array}$ & $\begin{array}{l}\text { colupulone } \\
\text { (\% rel.) }\end{array}$ \\
\hline 5164 Uran & 10.26 & 4.74 & 2.16 & 25.00 & 46.20 \\
\hline 5495 Juno & 4.17 & 3.46 & 1.21 & 38.70 & 63.30 \\
\hline 5512 Ceres & 4.81 & 2.87 & 1.68 & 37.00 & 57.40 \\
\hline 5540 Jupiter & 3.37 & 3.08 & 1.09 & 28.90 & 48.20 \\
\hline 5571 Eris & 5.17 & 3.87 & 1.34 & 36.90 & 62.80 \\
\hline No. 5652 & 6.16 & 5.34 & 1.15 & 35.10 & 56.70 \\
\hline No. 5656 & 8.01 & 3.03 & 2.64 & 39.50 & 59.30 \\
\hline HP111 Most ${ }^{a}$ & $7.5-9.5$ & $3.0-4.0$ & $2.3-2.5$ & $27-31$ & $32-50$ \\
\hline
\end{tabular}

a long-term range from crops 2017-2019

The highest content of hop-oil in 2019 was found in the genotypes No. $5656(1.58 \% \mathrm{w} / \mathrm{w})$ and Uran $(1.45 \%$ $\mathrm{w} / \mathrm{w})$; the genotype Most is long-term above the average of $1.00 \% \mathrm{w} / \mathrm{w}$ (see Table 3 ). On the contrary, the lowest content of hop oils was found in the genotype Jupiter, namely only $0.50 \% \mathrm{w} / \mathrm{w}$. The genotypes Most and Uran are characteristic of a high concentration of myrcene, whose long-term range in case of Most exceeds $60 \% \mathrm{w} / \mathrm{w}$. The difference from the other genotypes lies in lower percentage of caryophyllene; the genotype Uran has $6.27 \%$ rel. The highest percentage of caryophyllene was found in the genotype Jupiter (16.98\% rel.), which is the same for the genotypes Juno, Uran and especially for Most where there is the lowest percentage of humulene (lower than $1.00 \%$ rel.). Conversely, the genotypes Ceres, Eris, No. 5652 and No. 5656 are characteristic of a high percentage of humulene. Except the genotype 5540, the other ones contain a higher percentage of selinene. Some Czech varieties of hops also contain a higher percentage of selinene (Harmonie, Rubín, Vital, Gaia, Country, Mimosa etc.).

\section{Beer samples description}

It could be concluded, based on the comparison of chemical (Table 4) and sensory (data not shown) results that the basic character of the beer samples is very similar. These parameters are determined by the reproducible technological process which was the same for every beer sample. All samples had the medium carbonation and weak to medium fullness, which corresponds with the high degree of fermentation (the apparent fermentation degree ranged from 75.9 to $79.4 \%$ ).

Bitterness immediately after swallowing that was also very similar among the samples was weak. Then it culminated in the 15th second in the intensity of medium to strong, the variance among individual samples was 0.5 points on the scale from 0 to 5 , where 5 is maximum. The samples 9 and 10 prepared from the variety Most by the addition of this variety to the kettle had lower values of the bitterness culmination. Also, bitterness of these samples was a bit lower (approx. 4 BU lower) compared to the other samples. It could have been caused by a poorer transfer of alpha acids from Most pellets (compared to the Hercules extract in other samples) and also by

Table 3 Analysis of hop-oil in tested genotypes in 2019

\begin{tabular}{|l|c|c|c|c|c|c|}
\hline \multicolumn{1}{|c|}{ genotype } & $\begin{array}{c}\text { total content } \\
(\% \mathrm{w} / \mathrm{w})\end{array}$ & $\begin{array}{c}\text { myrcene } \\
\text { (\% rel.) }\end{array}$ & $\begin{array}{c}\text { caryophyllene } \\
\text { (\% rel.) }\end{array}$ & $\begin{array}{c}\text { farnesen } \\
\text { (\% rel.) }\end{array}$ & $\begin{array}{c}\text { humulene } \\
\text { (\% rel.) }\end{array}$ \\
\hline 5164 Uran & 1.45 & 42.10 & 6.27 & 13.10 & 7.27 \\
\hline 5495 Juno & 0.75 & 39.60 & 12.36 & $<0.1$ & 3.40 \\
\hline 5512 Ceres & 0.81 & 31.30 & 11.51 & 0.22 & 33.70 \\
\hline 5540 Jupiter & 0.50 & 31.60 & 16.98 & 0.47 & 8.00 \\
\hline 5571 Eris & 0.82 & 26.80 & 12.91 & $<0.1$ & 29.50 \\
\hline No. 5652 & 0.92 & 26.90 & 13.68 & $<0.1$ & 26.80 \\
\hline No. 5656 & 1.58 & 35.30 & 10.16 & 0.10 & 3.39 \\
\hline HP111 Most ${ }^{\mathrm{a}}$ & $1.00-1.60$ & $60-76$ & $4-5$ & $4-8$ & 4.40 \\
\hline
\end{tabular}

a long-term range from crops 2017-2019 
a higher fermentation degree of this sample (79.4\%) as a partial loss of bitterness is possible here. The intensity of the bitterness aftertaste (after 40th second) was about 1.5 lower than the bitterness culmination and had a similar trend for the beer samples as the culmination. The character of bitterness of the samples hopped with Most pellets (beer 9 and 10) was finer (average 2.3) than the other samples (beer 1-8) hopped with the extract of Hercules (average 3.0).

Astringency of most samples was very weak (around 1.0), samples 7 and 8 (genotypes No. 5656 and No. 5652) had bitterness of a weak intensity (higher than 1.5).

Sweetness and sourness were in all the samples well balanced and evaluated as low to middle. The overall impression of the beer samples was ranging from 2.9 to 3.1, also very good.

\section{Sensory analysis of hop aroma in beer samples}

The results of sensory analysis of aroma are given in the following text and spider graphs. In general, the hop aroma intensity of dry hopped beer samples is ranging from 2.4 to 3.6, where 2 is weak and 4 is strong. Among all compared samples, the character of hop aroma is fine and pleasant and often fresh. The beer 4 (Ceres) and beer 6 (Eris) deviate slightly from this characteristic as they are heavier and very intensive, respectively. Due to another technology of hopping of the beers 1,9 and 10, the final hop aroma is different, even though the same variety Most was used. The beers 9 and 10 were evaluated better than beer 1, pleasantness of hop aroma was evaluated as 4.1, 3.1 and 3.5, respectively (data not shown). Also, the combination with the Hercules extract slightly decreased the quality of the final hop aroma. From this pilot result can be deduced that a single hop technology is ideal for the variety Most.

Table 4 Basic chemical parameters of beer samples

\begin{tabular}{|c|c|c|c|c|c|c|c|c|c|c|c|c|}
\hline \multicolumn{13}{|c|}{ Beer No./genotype No. used for dry hopping } \\
\hline parameter & units & uncertainty & 1/HP111 & $2 / 5164$ & $3 / 5495$ & $4 / 5512$ & $5 / 5540$ & $6 / 5571$ & $7 / 5656$ & $8 / 5652$ & 9/HP111 & $10 /-$ \\
\hline Extract apparent & $\% \mathrm{w} / \mathrm{w}$ & 0.02 & 2.42 & 2.39 & 2.40 & 2.66 & 2.65 & 2.64 & 2.40 & 2.66 & 2.30 & 2.24 \\
\hline Extract real & $\% \mathrm{w} / \mathrm{w}$ & 0.06 & 4.02 & 3.99 & 4.00 & 4.27 & 4.27 & 4.26 & 4.00 & 4.27 & 3.95 & 3.9 \\
\hline Alcohol by mass & $\% \mathrm{w} / \mathrm{w}$ & 0.04 & 3.43 & 3.43 & 3.43 & 3.47 & 3.49 & 3.46 & 3.43 & 3.46 & 3.55 & 3.57 \\
\hline Alcohol by volume & $\% \mathrm{v} / \mathrm{v}$ & 0.05 & 4.38 & 4.38 & 4.38 & 4.44 & 4.46 & 4.43 & 4.38 & 4.43 & 4.53 & 4.55 \\
\hline Original extract & $\% \mathrm{w} / \mathrm{w}$ & 0.06 & 10.72 & 10.69 & 10.7 & 11.04 & 11.07 & 11.01 & 10.70 & 11.02 & 10.87 & 10.86 \\
\hline $\begin{array}{l}\text { Fermentation } \\
\text { apparent }\end{array}$ & $\%$ & 0.06 & 77.5 & 77.7 & 77.6 & 76.0 & 76.1 & 76.0 & 77.5 & 75.9 & 78.9 & 79.4 \\
\hline Fermentation real & $\%$ & 1.2 & 62.51 & 62.68 & 62.61 & 61.29 & 61.4 & 61.32 & 62.58 & 61.23 & 63.65 & 64.08 \\
\hline $\mathrm{pH}$ & & 0.05 & 4.36 & 4.32 & 4.35 & 4.33 & 4.34 & 4.35 & 4.26 & 4.26 & 4.30 & 4.30 \\
\hline Color & EBC & 0.5 & 13.8 & 13.7 & 13.4 & 13.6 & 13.7 & 13.3 & 13.5 & 13.4 & 13.3 & 12.9 \\
\hline Bitterness & $\mathrm{BU}$ & 1 & 28 & 32 & 30 & 28 & 28 & 29 & 28 & 29 & 26 & 24 \\
\hline iso-a-acids & $\mathrm{mg} / \mathrm{L}$ & $20 \%$ & 24.80 & 24.82 & 25.19 & 26.81 & 26.80 & 26.79 & 25.87 & 26.02 & 22.59 & 22.06 \\
\hline
\end{tabular}

\section{Beer 1 (HP 111 Most)}

Intensity of hop aroma: weak to medium (2.6)

Character of hop aroma: fine

Hop aroma: spicy (pepper), resinous (sweet woody, (sandalwood); weak herbal (thyme) and fresh citrusy (lemon).

Variety evaluation: Very pleasant hops suitable for dry hopping.

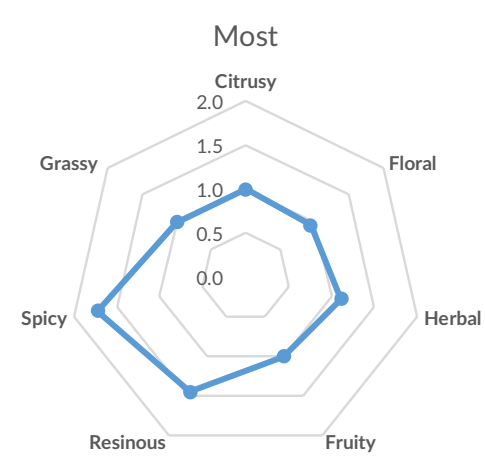




\section{Beer 2 (5164 Uran)}

Intensity of hop aroma: medium (3.2)

Character of hop aroma: fresh

Hop aroma: floral (jasmine, rose), resinous (fine woody), spicy (pepper, juniper), fruity (red fruits and tropical), herbal; weak citrusy and green tea.

Variety evaluation: Hops suitable for light summer beer or semi-dark beer

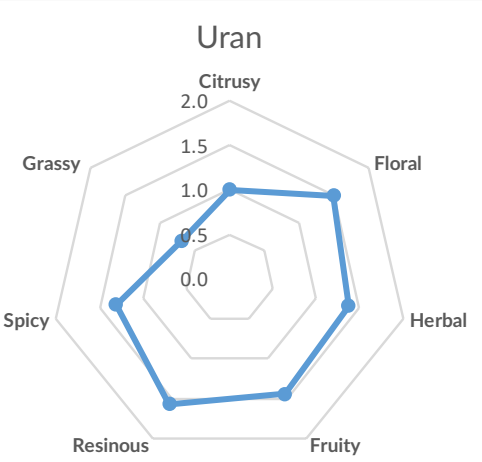

\section{Beer 3 (5495 Juno)}

Intensity of hop aroma: medium (2.8)

Character of hop aroma: pleasant

Hop aroma: spicy (pepper), resinous (woody), grassy (grass, cannabis), herbal (basil, mint and lemon balm); weak floral (rose, lavender), sulphury of low intensity in the background (rubber).

Variety evaluation: Hops suitable for more conservative top-fermented beer (British ale), or India Pale Lager.

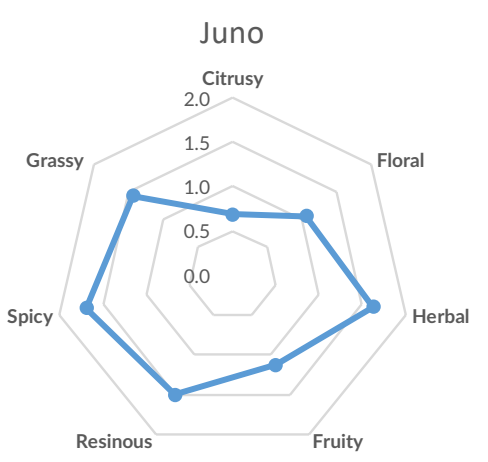

\section{Beer 4 (5512 Ceres)}

Intensity of hop aroma: medium (2.8)

Character of hop aroma: heavier

Hop aroma: resinous (woody), spicy (pepper, juniper), herbal (mint, parsley, chamomile), weak floral (rose, lavender), weak floral (rose), grassy and fruity (apricots and peaches); sulphury of very low intensity in the background (asphalt), rapidly disappearing. Variety evaluation: Hops suitable for English-type beer, usable at the end of hopping rather than dry hopping.

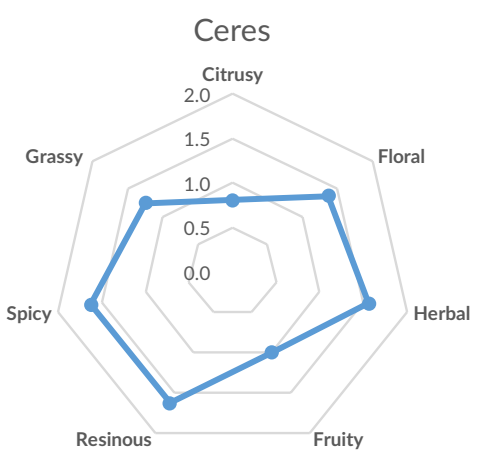

\section{Beer 5 (5540 Jupiter)}

Intensity of hop aroma: medium (3.2)

Character of hop aroma: light and fresh

Hop aroma: herbal (mint, chamomile), resinous (woody), spicy (juniper and pepper); weak grassy, very weak floral (rose) and citrusy (fresh lemon and oranges).

Variety evaluation: Hops suitable for IPA and APA beers.

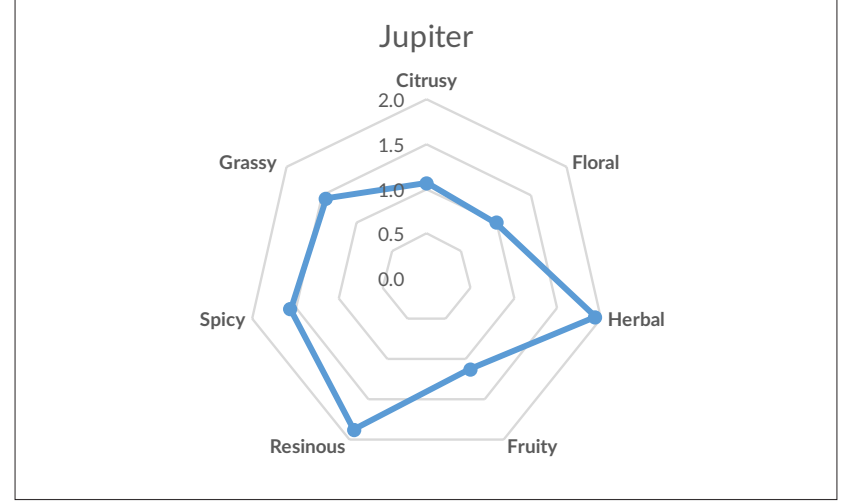




\section{Beer 6 (5571 Eris)}

Intensity of hop aroma: medium to strong (3.6)

Character of hop aroma: very intensive, fresh and fine Hop aroma: strong resinous (woody and pine), followed by herbal (parsley, rosemary and chamomile), spicy (juniper, cumin and pepper), grassy (dry grass, cannabis), weak citrusy (tangerine, lemon) and fruity (mostly tropical, apricot).

Variety evaluation: Hops suitable for stronger beer such as APA, Imperial IPA or Black IPA.

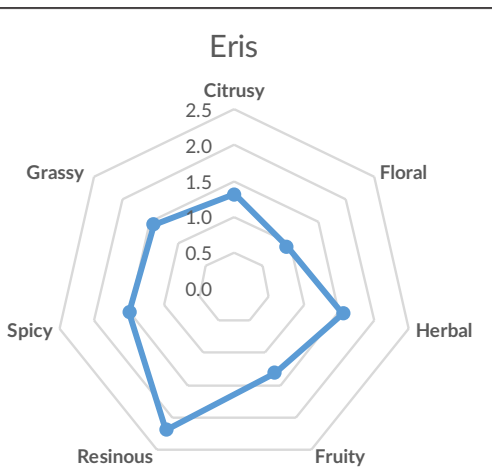

\section{Beer 7 (No. 5656)}

Intensity of hop aroma: medium (2.9)

Character of hop aroma: pleasant

Hop aroma: resinous (woody), herbal (chamomile, mint, parsley) and spicy (pepper, juniper); sulphury of low intensity in the background (asphalt), rapidly disappearing; weak earthy.

Special taste: rougher bitterness.

Variety evaluation: Hops suitable for both, traditional and dry hopping, where mixing with other varieties is possible.

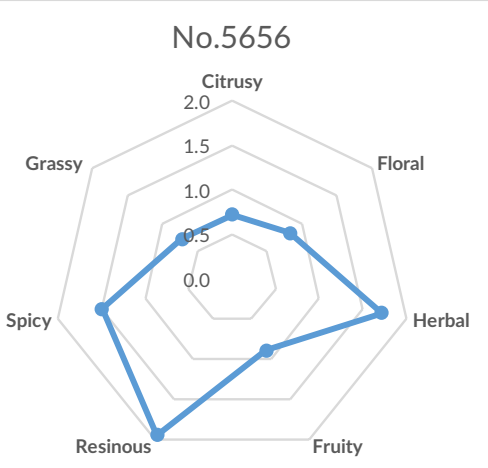

\section{Beer 8 (No. 5652)}

Intensity of hop aroma: medium (2.9)

Character of hop aroma: pleasant

Hop aroma: resinous (woody), fruity (tropical, red fruits and apricot), herbal (parsley, chamomile, wormwood), spicy (juniper, pepper) and floral (jasmine, rose).

Variety evaluation: The variety is suitable for light seasonal beers with high drinkability.

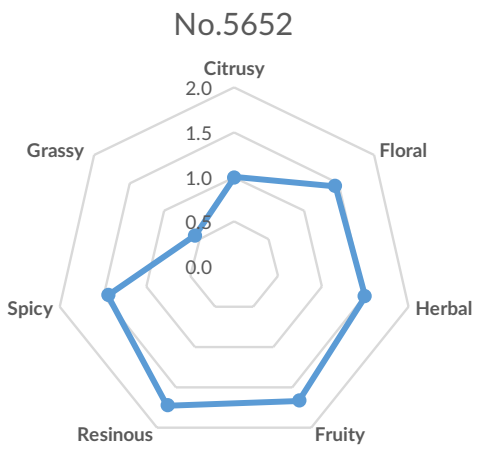

\section{Beer 9}

Intensity of hop aroma: weak to medium (2.4)

Character of hop aroma: pleasant

Hop aroma: herbal (parsley, chamomile, wormwood), spicy (juniper, pepper), resinous (woody); weak fruity (tropical, red fruits and apricot) and floral (jasmine, rose).

Variety evaluation: This variety is suitable for dry hopping of a whole range of top-fermented beers such as Pale Ale, APA, IPA and others.

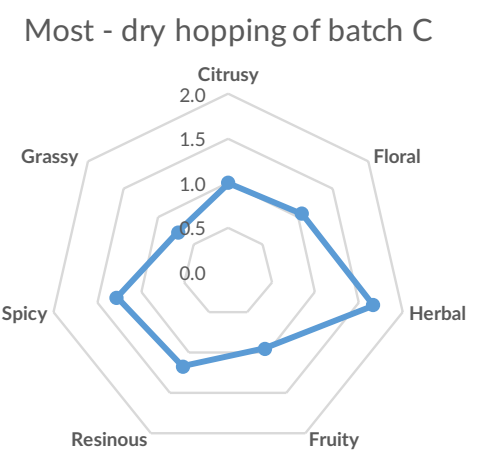




\section{Beer 10}

Intensity of hop aroma: weak (2.2)

Character of hop aroma: delicious, gentle

Hop aroma: resinous (woody, needle), citrusy (orange, tangerine), fruit (tropical fruits), herbal (thyme, mint), and spicy (pepper, juniper); weak and pleasant fruity (tropical fruits),

Variety evaluation: Due to a higher content of bitter acids, the variety is evidently suitable for single-hop beers, where it shows a delicate hop aroma and harmonious bitterness with a pleasant aftertaste.

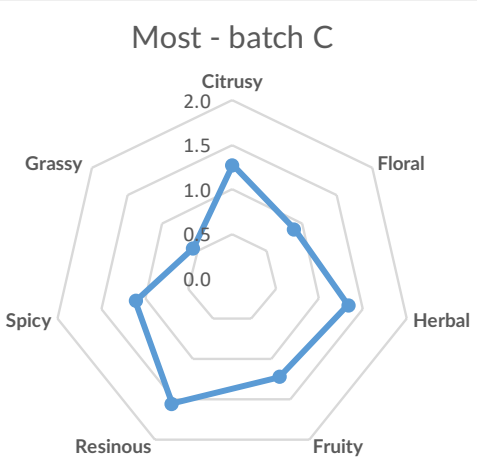

Table 5 Comparison of hop aroma in hops and related beer samples

\begin{tabular}{|c|c|c|}
\hline & Hop aroma & Beer aroma \\
\hline HP 111 Most & $\begin{array}{l}\text { fruity (tropical fruit, mango, peach, black currant), } \\
\text { light citrusy (grapefruit), spicy and hoppy }\end{array}$ & $\begin{array}{l}\text { spicy (pepper), resinous (sweet woody, sandal- } \\
\text { wood); weak herbal (thyme) and fresh citrusy } \\
\text { (lemon) }\end{array}$ \\
\hline 5164 Uran & $\begin{array}{c}\text { sharply hoppy, spicy (black pepper, curry, star } \\
\text { anise), vegetable (garlic, onion, olive), herbal, } \\
\text { needles }\end{array}$ & $\begin{array}{c}\text { floral (jasmine, rose), resinous (fine woody), spicy } \\
\text { (pepper, juniper), fruity (red fruits and tropical), } \\
\text { herbal; weak citrusy and green tea }\end{array}$ \\
\hline 5495 Juno & $\begin{array}{l}\text { sweety fruity (mango, banana, watermelon), } \\
\text { apple, orange, citrus, herbal }\end{array}$ & $\begin{array}{l}\text { spicy (pepper), resinous (woody), grassy (grass, } \\
\text { cannabis), herbal (basil, mint and lemon balm); } \\
\text { weak floral (rose, lavender), sulphury (rubber) }\end{array}$ \\
\hline 5512 Ceres & $\begin{array}{l}\text { fruity (apple, pear, orange) citrusy (grapefruit, } \\
\text { lime), resinous (woody, peel, tobacco), grassy } \\
\text { (tomato leaves, grass, nettle), herbal }\end{array}$ & $\begin{array}{c}\text { resinous (woody), spicy (pepper, juniper), herbal } \\
\text { (mint, parsley, chamomile), weak floral (rose, lav- } \\
\text { ender), grassy and fruity (apricots and peaches); } \\
\text { sulphury (asphalt) }\end{array}$ \\
\hline 5540 Jupiter & $\begin{array}{l}\text { floral (jasmine, rose), herbal (mint, lemon peel), } \\
\text { spicy, fruity (apple, peach) }\end{array}$ & $\begin{array}{l}\text { herbal (mint, chamomile), resinous (woody), spicy } \\
\text { (juniper and pepper); weak grassy, very weak } \\
\text { floral (rose) and citrusy (fresh lemon and oranges }\end{array}$ \\
\hline 5571 Eris & $\begin{array}{l}\text { citrusy (lime, grapefruit, tangerine, orange), citrus } \\
\text { flowers and peel, black currant), herbal }\end{array}$ & $\begin{array}{l}\text { strong resinous (woody and pine), herbal (parsley, } \\
\text { rosemary and chamomile), spicy (juniper, cumin } \\
\text { and pepper), grassy (dry grass, cannabis), weak } \\
\text { citrusy (tangerine, lemon) and fruity (mostly tropi- } \\
\text { cal, apricot) }\end{array}$ \\
\hline No. 5656 & fine aroma, fruity, floral and herbal & $\begin{array}{l}\text { resinous (woody), herbal (chamomile, mint, pars- } \\
\text { ley) and spicy (pepper, juniper); sulphury (asphalt), } \\
\text { weak earthy }\end{array}$ \\
\hline No. 5652 & $\begin{array}{l}\text { citrusy, tropical fruity (mango), herbal (mint), } \\
\text { resinous (needle) }\end{array}$ & $\begin{array}{l}\text { resinous (woody), fruity (tropical, red fruits and } \\
\text { apricot), herbal (parsley, chamomile, wormwood), } \\
\text { spicy (juniper, pepper) and floral (jasmine, rose) }\end{array}$ \\
\hline
\end{tabular}

Finally, a comparison of hop flavors in hops and related beers was performed. The changes in the hop aroma of the tested varieties during a brewing and hopping process are shown in Table 5 and were evaluated by Bayes' theorem. The probability of perceiving a particular hop aroma in beer given by perceiving the aroma in a hop was determined particularly for spicy $(100 \%)$, resinous (100\%), herbal (100\%) citrusy (40\%), floral (38\%), fruity (43\%) and grassy (100\%) aroma. The aroma such as spicy, resinous and herbal, was perceived in a final beer no matter which aromas were perceived in the related hops. These results give us an idea about transferring a hop aroma into beer during dry hopping techniques. It should be noted that these probabilities represent the point estimates, and their distributions are theoretically very wide due to a low number of observations used in the study. Therefore, these estimates are accompanied by a high degree of uncertainty. However, such estimations will be further clarified in a future project, where will be used in development of new beer recipes. 


\section{Conclusion}

It can be suggested, based on the results of this study that newly bred hop varieties can find a wide application in the brewing practice. Thus, the diversity of aromatic profiles of individual hop varieties approaches a wide range of beer styles, where the hop aroma must always suitably complement the malty character of the beer and consequently support the balanced overall impression. Simultaneously, the study provides important information on the transfer of a specific aroma from hops to beer. For the evaluation of this process there was developed a pilot method using Bayes' theorem, where the probability of perceiving a particular hop aroma in beer given by perceiving the aroma in a hop was determined. These probabilities represent the point estimates which are accompanied by a high degree of uncertainty because of a low number of observations used in the study. However, such estimations will be further clarified in the future project QK21010136, where this pilot method will be applied on various new hop varieties. Moreover, the transfer of hop aroma will be studied in this project on a molecular level.

\section{Acknowledgments}

This study was supported by the Ministry of Agriculture of the Czech Republic within the institutional support No. MZE-R01918 and within the collection of GZ hops, which is a part of the National Program for Conservation and Utilization of Plant Genetic Resources and Biodiversity (51834/2017-MZE-17253/6.2.1). The cooperation of co-authors was maintained by the support of the Technology Agency of the Czech Republic within the project TE02000177 "Center for Innovative Use and Strengthening of Competitiveness of Czech Brewery Raw Materials and Products".

The private Czech variety Most (with the working designation HP-111; formerly \# 1160) of Hopproducts, s.r.o. was bred in a frame of collaboration on a development program for new hop genotypes with the English company Charles Faram \& Co Ltd. All rights, licenses and registrations of the variety Most are owned by HOPPRODUCTS s.r.o.

\section{References}

Bayes, T., Price, R. (1763). An assay towards solving a problem in the doctrine of chances. Philosophical Transactions of the Royal Society of London, 53, 370-418.

EBC 7.7 (2012). $\alpha$ - and $\beta$-Acids in Hops and Hop Products by HPLC, In: EBC Analysis Committee-Nürnberg (ed.). Analytiva EBC, Hans Carl Get-ränke Fachverlag, Chap. 7.7.

EBC 9.4 (2004). Original, Real and Apparent Extract and Original Gravity of Beer, In: EBC Analysis Committee-Nürnberg (ed.). Analytiva EBC, Hans Carl Get-ränke Fachverlag, Chap. 9.4.

EBC 9.8 (2004). Bitterness of Beer, In: EBC Analysis Committee-Nürnberg (ed.). Analytiva EBC, Hans Carl Get-ränke Fachverlag, Chap. 9.8.

EBC 9.47 (2010). Iso- $\alpha$-acids and reduced iso- $\alpha$-acids (Rho, Tetra, Hexa) in beer by HPLC, In: EBC Analysis Committee-Nürnberg (ed.). Analytiva EBC, Hans Carl Get-ränke Fachverlag, Chap. 9.47.

Fric, V. (1992). Odrůdová skladba a ozdravovací proces chmele v ČSFR (eng. Varietal composition and healing process of hops in the Czechoslovak Socialist Republic). Chmelařství 11, 85-86.

Charvátová, J., Štefanová, L., Nesvadba, V. (2017). Collection of hop genetic resources in the Czech Republic. In: Weihrauch, F. (ed.) Proceedings of the Scientific-Technical Commission 25-29 June 2017, St. Stefan am Walde, Austria. Wolnzach: Scientific-Technical Commission of the International Hop Growers' Convention, p. 98.

Krofta, K. (2008). Hodnocení kvality chmele: Metodika pro praxi 4/2008. (eng. Evaluation of hop quality: Methodology for practice 4/2008.) Hop Research Institute, Ltd., Žatec, 52 pp. ISBN 978-80-86836-843 Available in Czech from: https://invenio.nusl.cz/record/170477/ files/nusl-170477_1.pdf

Nesvadba, V. (2018). Šlechtění chmele pro specifické vůně (eng. Hop breeding for a specific aroma). Chmelařská ročenka, 2018, 468-471.

Nesvadba, V., Charvátova J., Stefanova L. (2017). Hop Breeding in the Czech Republic. In: Proc. Scient. Comm., I.H.G.C., St. Stefan am Walde, Austria, 7-10.

Štěrba, K., Čejka, P., Čulík, J., Jurková, M., Krofta, K., Pavlovič, M., Mikyška, A, Olšovská, J. (2015). Determination of linalool in different hop varieties using a new method based on fluidized-bed extraction with gas chromatographic-mass spectrometric detection. Journal of the American Society of Brewing Chemists, 73(2), 151-158. https://doi. org/10.1094/ASBCJ-2015-0406-01 